\title{
Scaling up of Protocol for in vitro Multiplication and Conservation of Elite Genotype of Bacopa monnieri L. Pennell
}

\author{
Manmohan Sharma ${ }^{1}$, Mehak Gupta ${ }^{1 *}$, R.K. Salgotra ${ }^{1}$, Mamta Sharma ${ }^{1}$, \\ A.K. Singh ${ }^{1}$ and L.M. Gupta ${ }^{2}$ \\ ${ }^{1}$ School of Biotechnology, SKUAST-J, Chatha, Jammu-180009, India \\ ${ }^{2}$ Division of Agro Forestry, SKUAST-J, Chatha, Jammu-180009, India \\ *Corresponding author
}

\begin{tabular}{|l|}
\hline Ke y w o r d s \\
$\begin{array}{l}\text { Brahmi, Ayurvedic, } \\
\text { in vitro, Memory, } \\
\text { Medicinal and } \\
\text { endangered plant }\end{array}$ \\
\hline Article Info \\
\hline $\begin{array}{l}\text { Accepted: } \\
\text { 24 September } 2018 \\
\text { Available Online: } \\
\text { 10 October } 2018\end{array}$ \\
\hline
\end{tabular}

\section{A B S T R A C T}

Brahmi (Bacopa monnieri L.) belonging to the family Scrophulariaceae is an endangered perennial, glaburous, succulent creeping herb of great medicinal importance. Increased demand of Bacopa based drugs makes natural populations of this herb vulnerable to overexploitation. It is therefore essential to optimize and scale up in vitro multiplication protocols for conservation and multiplication of wild and cultivated germplasm. Nodal segments with axillary buds of an elite Bacopa genotype, were surface sterilized and inoculated to initiate aseptic cultures on 0.8 per cent agar semi-solidified MS medium (4.42 g/l) containing 3 per cent sucrose at pH 5.8. For initiating cultures medium was supplemented with different concentrations of BAP (2.0-4.0 mg/l) and kinetin (1.0-2.5 $\mathrm{mg} / \mathrm{l})$. The best results were observed on medium containing $2.5 \mathrm{mg} / \mathrm{l} \mathrm{BAP}$ and $1.5 \mathrm{mg} / 1$ Kinetin wherein 100 per cent bud breakage was observed. The maximum shoot proliferation $(10.4 \pm 0.50$ shoots/explant) and shoot length $(10.8 \pm 0.30 \mathrm{~cm})$ was observed on the same medium. To achieve more shoot length the medium was supplemented with $\mathrm{GA}_{3}(1.0-2.5 \mathrm{mg} / \mathrm{l})$ and the maximum shoot length $(16.6 \pm 0.29 \mathrm{~cm})$, number of shoots per explants (128.6 \pm 0.54$)$ and average number of leaves per shoot $(54.6 \pm 0.51)$ were observed in the medium containing $1.5 \mathrm{mg} / \mathrm{G} \mathrm{GA}_{3}$. For initiating rooting, cultures were shifted to both semi-solidified and liquid medium with varying strengths of MS salts as well IBA concentrations (0.5-1.5 mg/l). The maximum numbers of roots/shoot $(13.2 \pm 0.39)$ and root length $(6.6 \pm 0.31 \mathrm{~cm})$ were observed in $1 / 2$ strength liquid MS medium supplemented with IBA $1.0 \mathrm{mg} / \mathrm{l}$. The rooted plantlets were hardened under controlled conditions along with application of $1 / 2$ strength liquid medium during first two days of ex-vitro acclimatization and 100 per cent survival was achieved. The tissue culture raised plants were shifted to pots and found to be superior with respect to agronomic traits in comparison to naturally propagated plants.

\section{Introduction}

Bacopa monnieri (L.) Pennel a small, annual, creeping herb commonly called as 'Brahmi', belongs to the family Scrophulariaceae. It grows in wet tropical environments, mainly distributed in damp and marshy tracts in the subtropical region of the Indian subcontinent. It requires a well-drained, moist, sandy loam soil, rich in organic matter and grows well at a 
temperature range of $30^{\circ} \mathrm{C}$ to $40^{\circ} \mathrm{C}$. Brahmi is an important Ayurvedic medicinal herb used for the improvement of intelligence, memory and revitalization of sensory organ. The plant has been used for its cardiotonic, antiinflammatory, analgesic, antipyretic, anticancerous, anticonvulsive and antioxidant properties since historic times. Besides, it has also been used in treatment of insomnia, asthma, hoarseness, snake bite, rheumatism, leprosy, eczema, water retention, blood cleaning and insanity. The medicinal properties of Bacopa monnieri have been attributed to the presence of different types of saponins such as Bacosides (A, B, C and D) called the memory chemicals, which are responsible for improving memory related functions (Kharde et al., 2017). B. monnieri also has the ability to phytoremediate toxic heavy metals (e.g. cadmium, chromium and mercury) from aquatic bodies by absorbing and accumulating these metals in their shoots and roots (Hussain et al., 2011). On the basis of medicinal uses, commercial value and potential for further research and development, $B$. monnier $i$ is designated as the second most important medicinal plant of India (Shrivastava et al., 1999).

Brahmi has a high market demand due to its medicinal properties. Estimated consumption of this drug in India is about 1000 tons per year (Tripathi et al., 2012). The natural regeneration of this plant is hampered by death of the plant at two leaf stage and specific habitat requirement. Bacopa monnieri is categorized as one of the highly endangered medicinal plant in India (Anonymous, 2007). Moreover, because of the heavy demand and short supply, it is the most adulterated species in Ayurvedic formulations. More than 90 percent of medicinal plant species used by the industry are however collected from the wild source of which 70 percent involve unorganized harvesting. This factor poses a serious threat to the genetic stock and the biodiversity of medicinal plants. So, there is need to find the alternative technologies to enhance the production of Brahmi. In the present scenario, plant tissue culture is an attractive alternative approach to regenerate and conserve Brahmi for future needs. Therefore, the present study was undertaken to develop a reproducible protocol and upscale it for faster in vitro propagation from nodal segments with axillary buds.

\section{Materials and Methods}

In the present investigation, Murashige and Skoog's (1962) basal medium was used for initiating in vitro culture and their subsequent proliferation. For the preparation of a given volume of MS medium, MS basal medium powder $(4.42 \mathrm{~g} / \mathrm{l})$ having macronutrients, micronutrients, vitamins and iron source, procured from HiMedia Industries, Mumbai (India), was added to the known volume of double distilled water. The $\mathrm{pH}$ of medium was adjusted between 5.6-5.8 using $0.1 \mathrm{~N} \mathrm{NaOH}$ or $0.1 \mathrm{~N} \mathrm{HCl}$. Prepared $5 \mathrm{X}$ stocks of growth regulators such $\mathrm{BAP}, \mathrm{KN}, \mathrm{GA}_{3}$ and IBA (Indole-3-Butyric acid) were added to it in different concentrations. To this solution 30 $\mathrm{g} / \mathrm{l}$ sucrose and $0.8 \mathrm{~g} / \mathrm{l}$ agar was added, and the solution was heated till agar got dissolved completely. After cooling, about $50 \mathrm{ml}$ of this medium was dispensed in $250 \mathrm{ml}$ Borosil conical flasks which were plugged properly and tightly with sterilized non-absorbent cotton plugs. Finally, these culture flasks containing nutrient medium were steam sterilized at 15 psi pressure at $121^{\circ} \mathrm{C}$ for $15-20$ minutes in an autoclave. These cultural vessels with semisolid medium were kept in dark at room temperature $\left(25 \pm 2^{\circ} \mathrm{C}\right)$ for one week before using for inoculation. The explants were excised from authentic plants of Bacopa monnieri L (Fig. 1a) being maintained at Herbal Garden, Division of Agroforestry, SKUAST-Jammu. These explants were firstly washed under a jet of running tap water in 
order to remove dust, dirt and other unwanted materials. They were then washed by a detergent solution (Labolenne) containing 2-3 drops of a wetting agent (Tween 20). This was followed by washing with tap water to remove the detergent. The explants were treated with 2g/l Dithane M-45 and 1 g/l Bavistin for 15-20 minutes with intermittent shaking followed by washing with running tap water to remove traces of fungicides. This was followed by rinsing 2-3 times with distilled water. Finally the explants were sterilized with freshly prepared 0.1 percent $\mathrm{HgCl}_{2}$ solution for different time intervals. The surface sterilized explants were then washed 5-6 times with autoclaved double distilled water so as to remove the last traces of the sterilant. The sterilized explants were then put into preautoclaved petri-dishes, cut into suitable size and finally aseptically inoculated into the culture media supplemented with different combinations of growth hormones. Each treatment involved about 10-20 explants and each experiment were replicated thrice. The cultures were incubated inside the culture room at $25 \pm 2^{\circ} \mathrm{C}$, with a $16 \mathrm{~h}$ photoperiod provided with cool white fluorescent tubes (Phillips, India), under light intensity of 3K lx to $5 \mathrm{~K} 1 \mathrm{x}$.

\section{Axillary shoot proliferation and elongation}

Surface sterilized nodal explants were cultured on either Murashige and Skoog's (MS) medium alone or MS medium supplemented with different concentrations of BAP (2.0- 4.0 $\mathrm{mg} / \mathrm{l})$ and $\mathrm{KN}(1.0-2.5 \mathrm{mg} / \mathrm{l})$ for shoot/shoot bud induction. After four weeks of culture, the swollen nodal explants with elongated shoots and large number of shoot buds cultured on optimal shoot induction medium, $\mathrm{MS}+2.0$ $\mathrm{mg} / \mathrm{l} \mathrm{BAP}+1.5 \mathrm{mg} / \mathrm{l} \mathrm{KN}$, were subcultured either by cutting them transversely or as such (without cutting) on MS supplemented with different concentrations of GA3 (1.0 -2.5 $\mathrm{mg} / \mathrm{l})$ with the aim of further shoot proliferation and elongation. All the media used for axillary shoot proliferation were augmented with 3 percent sucrose and 0.8 percent agar (Hi- Media, Industries, Mumbai, India). The $\mathrm{pH}$ of the media was adjusted to 5.6-5.8 before autoclaving at $121^{\circ} \mathrm{C}$ for 20 min.

\section{Rooting of in vitro regenerated shoots}

The healthy in vitro regenerated shoots were excised and taken for in vitro rooting. For this, the harvested shoots were inoculated on either half strength of MS or full strength of MS liquid medium. The medium was supplemented with different concentrations $(0.5-1.5 \mathrm{mg} / \mathrm{l})$ of IBA.

\section{Ex vitro hardening of healthy plants}

In vitro rooted plantlets were taken out from the culture vessels and sticky semi solid medium was removed carefully from the roots under running tap water. The plantlets were then directly transferred to the clay/plastic pots $(20 \times 25 \mathrm{~cm})$ containing sterilized potting mixtures $\{$ Sand and Soil $(1: 1)$, Sand, Soil and FYM (1:1:1) and Coco peat $\}$. The pots were kept in green house under controlled climatic conditions for two weeks prior to transfer to outdoor. The pots were irrigated with liquid $1 / 2$ MS salt solution for initial two days. Liquid $1 / 2$ MS solution was prepared in tap water. After three weeks of ex vitro transfer to pots, data were recorded for total number of plants that survived, total number of shoots and average shoot length.

\section{Data recording and analysis}

Experiments for shoot bud induction, shoot proliferation and rooting of in vitro regenerated shoots were replicated three times. Fifteen flasks were used having two explants in each flask for shoot bud induction. Five flasks, each having one explant, were taken 
for shoot proliferation, elongation and root induction experiments. The data including average number of shoots/explant, average number of roots, average length of shoot and root were recorded at weekly intervals. All data were subjected to Analysis of Variance (ANOVA) in a completely randomized design (CRD). The differences among the treatment means were tested by Tukey-Kramer Multiple range test. The data were analyzed using Dell STATISTICA v.0 13.2 software.

\section{Results and Discussion}

\section{Effect of 0.1 percent $\mathrm{HgCl}_{2}$ treatment on explants at different time intervals}

It was observed that by gradually increasing the time duration of 0.1 percent $\mathrm{HgCl}_{2}$ treatment of explants from 2 mins to 7 mins, percentage of infection decreased in the cultures and simultaneously percentage of their regeneration increased (Table 1). Thereafter, at 10 mins 0.1 percent $\mathrm{HgCl}_{2}$ treatment, 60 percent of explants were killed and only 40 percent were able to regenerate. Amongst the different time intervals of 0.1 percent $\mathrm{HgCl}_{2}$ treatment, 7 mins treatment proved effective as there was no mortality of explants, no infection in cultures and 100 percent cultures were established and regenerated.

\section{Induction and proliferation of shoot buds}

It was observed that addition of cytokinins (BAP and $\mathrm{KN}$ ) to $\mathrm{MS}$ medium was not essential for bud break from nodal explants. MS medium devoid of any growth regulator exhibited 100 percent bud break in 4-6 days and an average of $2.0 \pm 0.01$ shoots per explant were regenerated in four weeks (Fig. 1b). Further, on MS medium supplemented with different concentrations of BAP and $\mathrm{KN}$, bud break was achieved in cent percent explants after one week of inoculation and it was found that only two shoots were elongated irrespective of medium tested. In this study, an interesting observation was made in all the BAP and KN supplemented media that gradually the base of the nodal region became swollen, numerous shoot buds were initiated (both above and below the medium), of which only few shoot buds (above the medium) were elongated in the same medium. Amongst the different concentrations of BAP and $\mathrm{KN}$ tested, $2.5 \mathrm{mg} / \mathrm{l} \mathrm{BAP}$ and $1.5 \mathrm{mg} / \mathrm{l} \mathrm{KN}$ (shoot induction medium) proved significantly better than other treatments with maximum of 10.4 shoots/explant and shoot length of $10.8 \mathrm{~cm}$ (Table 2).

\section{Refinement of media for proliferation and elongation of shoot buds induced from nodal explants}

A number of shoot buds were initiated on BAP and KN supplemented optimal media (MS+ BAP+KN) (Fig. 2a). However, most of them failed to elongate in the same medium excepting a few. The enlarged nodal region with induced shoot buds was transversely cut and sub-cultured on optimal MS media supplemented with different concentrations of $\mathrm{GA}_{3}$ for elongation of shoots. Varying lengths of shoots were observed (Fig. 2b) but the best response was observed when the uncut nodal segments were subcultured on MS medium augmented with $1.5 \mathrm{mg} / \mathrm{l} \quad \mathrm{GA}_{3}$, where maximum of 128.6 shoots /explant with an average length of $16.6 \mathrm{~cm}$ (Fig. 2c) were recorded after three weeks of sub-culture (Table 3 and Fig. 1c, 1d).

\section{Rooting of in vitro regenerated shoots}

The healthy in vitro regenerated shoots were cultured on growth regulator free $1 / 2 \mathrm{MS}$ or MS medium supplemented with different concentration of IBA (0.5-1.5 mg /1). Cent per cent rooting was observed within one week of shoot inoculation in all the media tested. In 
MS medium supplemented with $1.0 \mathrm{mg} / \mathrm{l} \mathrm{IBA}$, 8.8 roots per shoot with an average root length of $4.9 \mathrm{~cm}$ was observed. On the other hand, maximum rooting was noted in $1 / 2 \mathrm{MS}+1.0$ $\mathrm{mg} / \mathrm{l}$ IBA, where an average of 13.2 roots/shoot with an average root length of 6.6 $\mathrm{cm}$ was recorded (Table 4 and Fig. 1e).

\section{Acclimatization of plantlets}

Irrespective of the planting out media, all the regenerated plantlets were successfully acclimatized in green house. In the present study, 80-100 per cent survival under ex vitro controlled plant growth conditions was easily achieved in $B$. monnieri on using different potting mixtures (Table 5). For initial two days, liquid $1 / 2 \mathrm{MS}$ was sprayed on in vitro regenerated plantlets. The best response amongst the potting mixture combinations used on growth parameter was observed with Sand + Soil+ FYM (1:1:1) planting media wherein the average shoot length was recorded as $10.5 \pm 0.41 \mathrm{~cm}$ after three weeks of transplanting in pots (Fig. 1f).

Tissue culture technology offers an alternative method for the conservation of germplasm as well as micropropagation of medicinally important plant resources (Witbooi et al., 2017; Purohit et al., 2017 and Shahzad et al.,
2017). In the present study, sterilization protocol was optimized using 0.1 percent mercuric chloride at different time intervals. Mercury ions in $\mathrm{HgCl}_{2}$ solution work in sterilization by interfering with enzymes and protein in the cell membrane and cytoplasm of microorganisms (Smith, 2005). Maximum sterilization with least contamination and higher survival rate of nodal segments has been obtained by using 0.1 percent mercuric chloride for 7 mins. It was noticed that increasing the time duration of treatment with 0.1 percent mercuric chloride yielded lesser contamination but higher mortality rate. Hence, it is concluded that sterilization treatment of mercuric chloride $(0.1 \%)$ for 7 mins is effective and optimum for field grown Brahmi plants intended for in vitro culture. Many researchers have reported in vitro propagation of $B$. monnieri with nodal segment (Behera et al., 2015; Mohanta and Sahoo, 2014; Rathore and Singh, 2013; Kaur et al., 2013; Mehta et al., 2012 and Ceasar et al., 2010).

Nodal segment is usually the preferred explant for in vitro clonal propagation as the cells of axillary meristem in the nodal segment undergo continuous and rapid mitosis so that the resulting shoots are less vulnerable to infection and genetic changes.

Table.1 Effect of 0.1 percent $\mathrm{HgCl}_{2}$ treatment on culture establishment on growth regulator free MS media

\begin{tabular}{|c|c|c|c|}
\hline $\begin{array}{c}\text { Duration of } \\
\text { treatment (in mins) }\end{array}$ & $\begin{array}{c}\text { percentage of } \\
\text { infected cultures }\end{array}$ & percentage mortality & $\begin{array}{l}\text { percentage of cultures } \\
\text { regenerated }\end{array}$ \\
\hline- & 90 & 0 & 10 \\
\hline $\mathbf{2}$ mins & 75 & 0 & 25 \\
\hline $\mathbf{3}$ mins & 65 & 0 & 35 \\
\hline $\mathbf{5}$ mins & 50 & 0 & 50 \\
\hline 7 mins & $\mathbf{0}$ & $\mathbf{0}$ & $\mathbf{1 0 0}$ \\
\hline 10 mins & 0 & 60 & 40 \\
\hline
\end{tabular}

* Data collected at 2 weeks of culture 
Table.2 Effect of cytokinins on shoot regeneration from nodal segments of Bacopa monnieri L.

\begin{tabular}{|c|c|c|c|}
\hline \multicolumn{2}{|c|}{ Cytokinin (mg/l) } & \multirow{2}{*}{$\begin{array}{l}\text { Average No. of } \\
\text { shoots/ explant }\end{array}$} & \multirow{2}{*}{$\begin{array}{l}\text { Average shoot } \\
\text { length }(\mathrm{cm})\end{array}$} \\
\hline $\begin{array}{c}\text { BAP } \\
(\mathrm{mg} / \mathrm{l})\end{array}$ & $\begin{array}{c}\mathrm{KN} \\
(\mathrm{mg} / \mathrm{l})\end{array}$ & & \\
\hline- & - & $2.0 \pm 0.01^{\mathrm{a}}$ & $2.1 \pm 0.10^{\mathrm{a}}$ \\
\hline 2.0 & \multirow[t]{5}{*}{-} & $2.3 \pm 0.51^{\mathrm{ab}}$ & $3.4 \pm 0.11^{b c}$ \\
\hline 2.5 & & $3.3 \pm 0.52^{a b}$ & $3.6 \pm 0.41^{c}$ \\
\hline 3.0 & & $3.0 \pm 0.89^{\mathrm{ab}}$ & $3.9 \pm 0.20^{c}$ \\
\hline 3.5 & & $3.0 \pm 0.01^{\mathrm{ab}}$ & $3.9 \pm 0.19^{c}$ \\
\hline 4.0 & & $3.0 \pm 0.04^{\mathrm{ab}}$ & $4.1 \pm 0.25^{c}$ \\
\hline \multirow[t]{4}{*}{-} & 1.0 & $2.0 \pm 0.03^{\mathrm{a}}$ & $2.1 \pm 0.05^{\mathrm{a}}$ \\
\hline & 1.5 & $2.3 \pm 0.52^{a b}$ & $2.3 \pm 0.02^{a}$ \\
\hline & 2.0 & $2.6 \pm 0.51^{a b}$ & $2.5 \pm 0.08^{\mathrm{a}}$ \\
\hline & 2.5 & $3.5 \pm 0.54^{b c}$ & $2.6 \pm 0.10^{\mathrm{ab}}$ \\
\hline \multirow[t]{4}{*}{2.0} & 1.0 & $5.0 \pm 0.36^{\mathrm{de}}$ & $6.7 \pm 0.49^{d}$ \\
\hline & 1.5 & $4.8 \pm 0.57^{\text {ce }}$ & $7.1 \pm 0.47^{d}$ \\
\hline & 2.0 & $5.3 \pm 0.52^{\text {def }}$ & $8.0 \pm 0.30^{\mathrm{e}}$ \\
\hline & 2.5 & $5.7 \pm 0.51^{\operatorname{defg}}$ & $8.9 \pm 0.35^{\text {thk }}$ \\
\hline \multirow[t]{4}{*}{2.5} & 1.0 & $7.7 \pm 0.50^{\text {hklmn }}$ & $9.4 \pm 0.47^{\text {fghj }}$ \\
\hline & 1.5 & $10.4 \pm 0.50^{j}$ & $10.8 \pm 0.30^{i}$ \\
\hline & 2.0 & $9.3 \pm 0.33^{\mathrm{ij}}$ & $10.0 \pm 0.28^{\text {gij }}$ \\
\hline & 2.5 & $9.0 \pm 0.43^{\text {hij }}$ & $9.9 \pm 0.18^{g j}$ \\
\hline \multirow[t]{4}{*}{3.0} & 1.0 & $8.7 \pm 0.51^{\mathrm{hjk}}$ & $9.7 \pm 0.18^{\mathrm{tg} j}$ \\
\hline & 1.5 & $8.4 \pm 0.14^{\mathrm{hjkl}}$ & $9.4 \pm 0.17^{\text {thj }}$ \\
\hline & 2.0 & $7.7 \pm 0.16^{\text {hklmn }}$ & $9.3 \pm 0.05^{\text {thjk }}$ \\
\hline & 2.5 & $7.3 \pm 0.15^{\mathrm{klmn}}$ & $9.2 \pm 0.12^{\text {thk }}$ \\
\hline \multirow[t]{4}{*}{3.5} & 1.0 & $8.0 \pm 0.44^{\text {hjkln }}$ & $9.2 \pm 0.04^{\text {thjk }}$ \\
\hline & 1.5 & $7.4 \pm 0.41^{\mathrm{klmn}}$ & $9.1 \pm 0.15^{\text {thk }}$ \\
\hline & 2.0 & $6.7 \pm 0.51^{\text {fgmn }}$ & $9.0 \pm 0.07^{\text {thk }}$ \\
\hline & 2.5 & $6.3 \pm 0.04^{\mathrm{dfgm}}$ & $8.9 \pm 0.15^{\mathrm{hk}}$ \\
\hline \multirow[t]{4}{*}{4.0} & 1.0 & $7.0 \pm 0.48^{\mathrm{glmn}}$ & $8.8 \pm 0.03^{h k}$ \\
\hline & 1.5 & $6.8 \pm 0.52^{g m n}$ & $8.8 \pm 0.11^{\mathrm{hk}}$ \\
\hline & 2.0 & $6.5 \pm 0.35^{\mathrm{fgm}}$ & $8.8 \pm 0.06^{\mathrm{hk}}$ \\
\hline & 2.5 & $6.3 \pm 0.19^{\mathrm{fgm}}$ & $8.6 \pm 0.19^{\mathrm{ek}}$ \\
\hline
\end{tabular}

In a column, different letters in superscripts indicate statistically significant difference between the means $(P<0.05$; Tukey-Kramer Multiple Comparisons Test).

* Data collected at 4 weeks of culture. 
Table.3 Effect of cytokinins and $\mathrm{GA}_{3}$ on shoot proliferation and elongation from in vitro raised shoots of Bacopa monnieri L.

\begin{tabular}{|c|c|c|c|c|c|}
\hline \multicolumn{2}{|c|}{ Cytokinin (mg/l) } & \multirow[t]{2}{*}{$\mathrm{GA}_{3}(\mathrm{mg} / \mathrm{l})$} & \multirow[t]{2}{*}{ Shoots / explant } & \multirow{2}{*}{$\begin{array}{l}\text { Shoot length } \\
\qquad(\mathrm{cm})\end{array}$} & \multirow[t]{2}{*}{ leaves / shoot } \\
\hline $\begin{array}{l}\text { BAP } \\
(\mathrm{mg} / \mathrm{l})\end{array}$ & $\begin{array}{l}\mathrm{KN} \\
(\mathrm{mg} / \mathrm{l})\end{array}$ & & & & \\
\hline \multirow[t]{4}{*}{2.5} & \multirow[t]{4}{*}{1.5} & 1.0 & $95.4 \pm 0.54$ & $14.3 \pm 0.31$ & $23.8 \pm 0.42$ \\
\hline & & 1.5 & $128.6 \pm 0.54$ & $16.6 \pm 0.29$ & $54.6 \pm 0.51$ \\
\hline & & 2.0 & $118.6 \pm 0.54$ & $15.7 \pm 0.19$ & $31.7 \pm 0.48$ \\
\hline & & 2.5 & $105.6 \pm 0.54$ & $15.2 \pm 0.04$ & $27.5 \pm 0.52$ \\
\hline
\end{tabular}

Statistically significant difference between the means calculated at $P<0.001$ by Tukey-Kramer Multiple Comparisons Test.

* Data collected at 3 weeks of culture.

Table.4 Effect of auxin IBA on root induction from in vitro raised shoots of Bacopa monnieri L.

\begin{tabular}{|c|c|c|c|c|}
\hline Media & \multicolumn{1}{|l|}{$\begin{array}{l}\text { IBA } \\
(\mathbf{m g} / \mathbf{l})\end{array}$} & $\begin{array}{c}\text { percentage of cultures } \\
\text { forming useful roots }\end{array}$ & Roots/ shoot & $\begin{array}{c}\text { Root length } \\
(\mathbf{c m})\end{array}$ \\
\hline \multirow{2}{*}{ MS } & - & 100 & $5.7 \pm 0.05$ & $2.8 \pm 0.2$ \\
& 0.5 & 100 & $7.2 \pm 0.14$ & $3.7 \pm 0.31$ \\
\hline & 1.0 & 100 & $8.8 \pm 0.42$ & $4.9 \pm 0.20$ \\
\hline $1 / 2$ MS & 1.5 & 100 & $8.0 \pm 0.50$ & $4.4 \pm 0.30$ \\
\hline & - & 100 & $9.6 \pm 0.09$ & $3.6 \pm 0.31$ \\
\hline & 0.5 & 100 & $12.3 \pm 0.16$ & $4.3 \pm 0.28$ \\
\hline & 1.0 & $\mathbf{1 0 0}$ & $\mathbf{1 3 . 2 \pm 0 . 3 9}$ & $\mathbf{6 . 6 \pm 0 . 3 1}$ \\
\hline & 1.5 & 100 & $11.3 \pm 0.41$ & $5.2 \pm 0.33$ \\
\hline
\end{tabular}

Statistically significant difference between the means calculated at $P<0.05$ by Tukey-Kramer Multiple Comparisons Test.

* Data collected at 3 weeks of culture.

Table.5 Effect of planting out media on survival of micro propagated plantlets of Bacopa monnieri L. during hardening

\begin{tabular}{|l|c|c|}
\hline Planting out media & $\begin{array}{l}\text { Percentage of } \\
\text { plants survived }\end{array}$ & Shoot length \\
\hline Sand +Soil $(1: 1)$ & 80 & $8.3 \pm 0.30$ \\
\hline Sand + Soil+ FYM $(1: 1: 1)$ & $\mathbf{1 0 0}$ & $\mathbf{1 0 . 5} \pm \mathbf{0 . 4 1}$ \\
\hline Coco peat & 90 & $6.9 \pm 0.11$ \\
\hline
\end{tabular}

Statistically significant difference between the means calculated at $P<0.05$ by Tukey-Kramer Multiple Comparisons Test.

* Data collected at 3 weeks of culture.

\#1/2MS Liquid was sprayed for 2 days 
Fig.1 Stages of in vitro propagation of Brahmi (Bacopa monneri) plant. a) mother plant, b) Shoot initiation from nodal explants on shoot induction media, c) Shoot elongation and proliferation on $2.5 \mathrm{mg} / \mathrm{l} \mathrm{BAP}+1.5 \mathrm{mg} / \mathrm{KN}+1.5 \mathrm{mg} / \mathrm{l} \mathrm{GA}_{3}$ Media, d) Hardening/acclimatization of plants

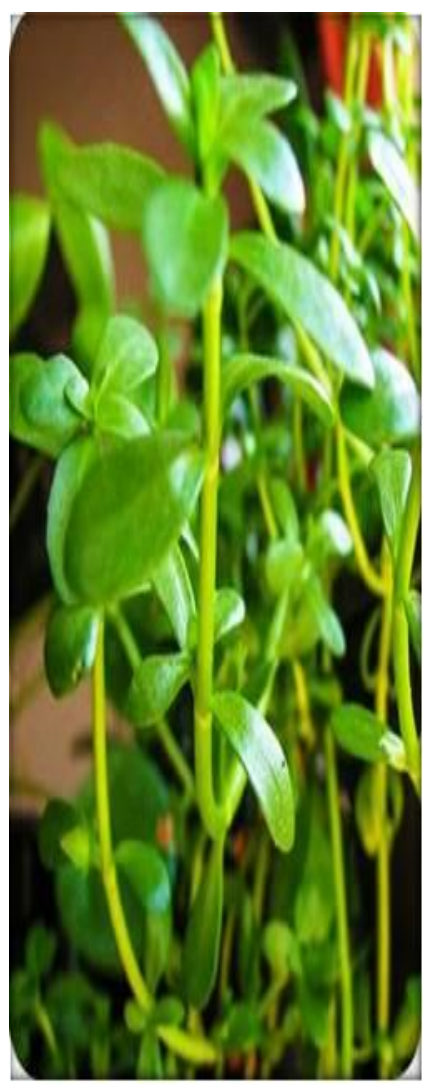

a

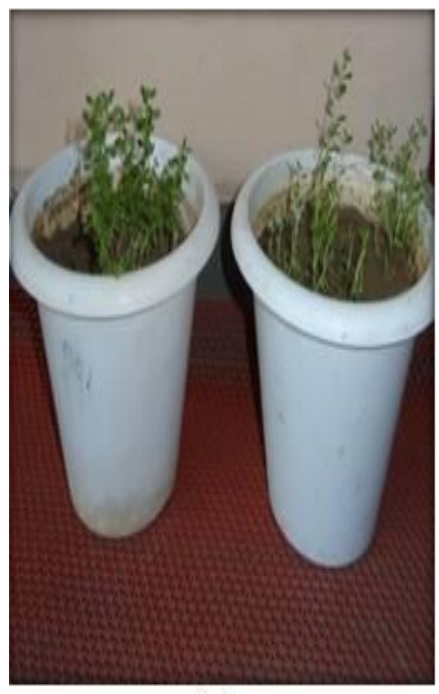

f
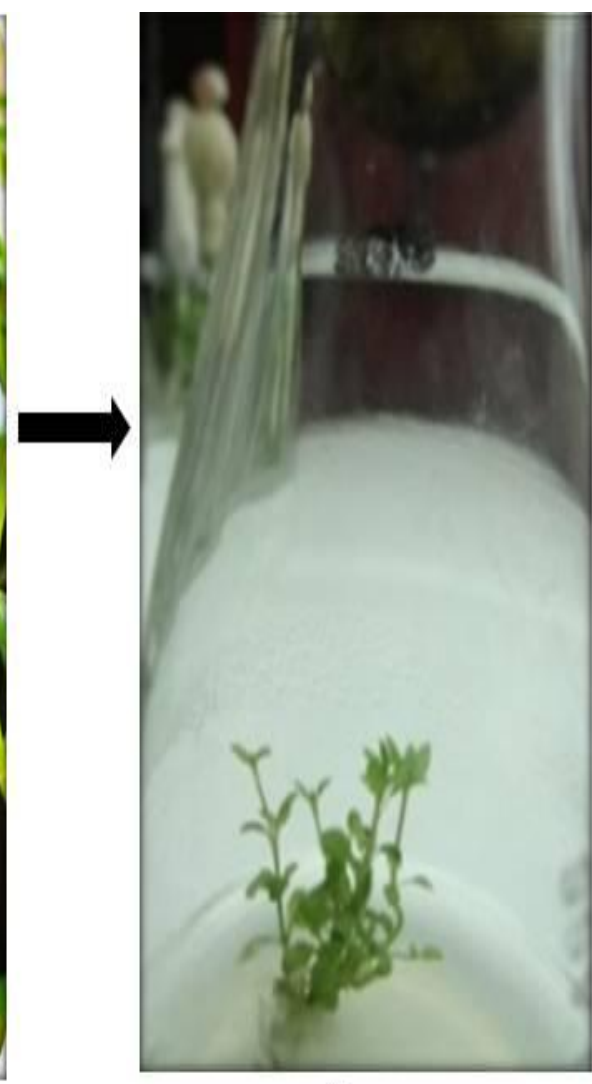

b

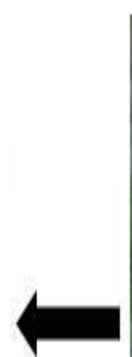

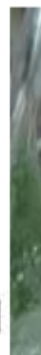

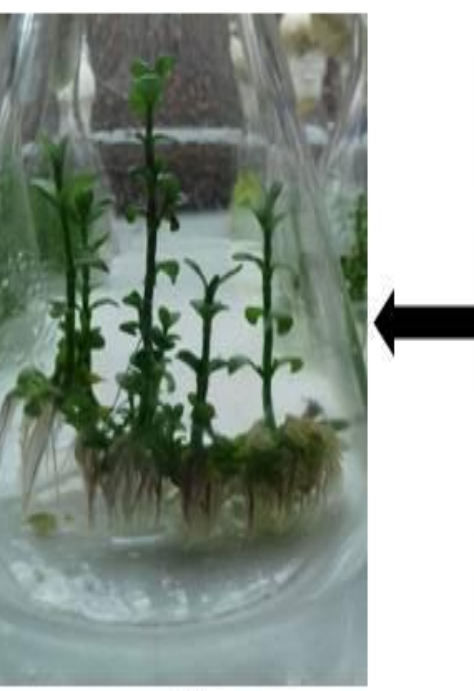

e
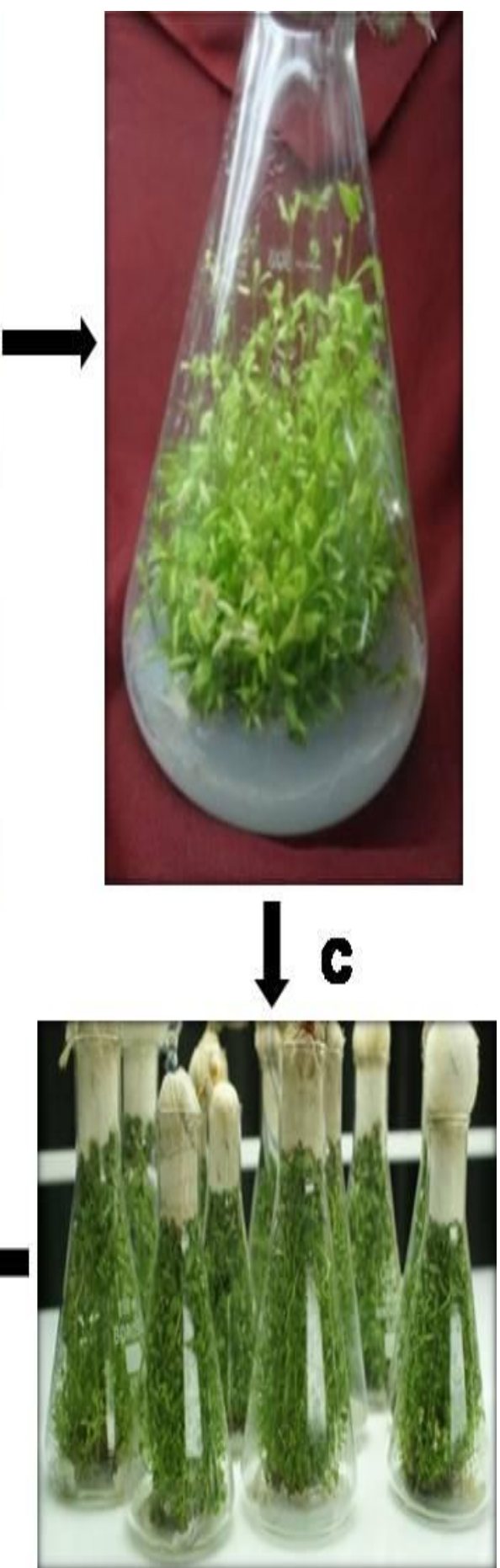

d 
Fig.2 Effect of $\mathrm{GA}_{3}$ on shoots elongation. a) Shoot proliferation in optimum media, b) Varying lengths of shoots obtained at different concentrations of $\mathrm{GA}_{3}$, and c) Maximum length of shoot observed on medium standardized with $1.5 \mathrm{mg} / \mathrm{l} \mathrm{GA}_{3}$

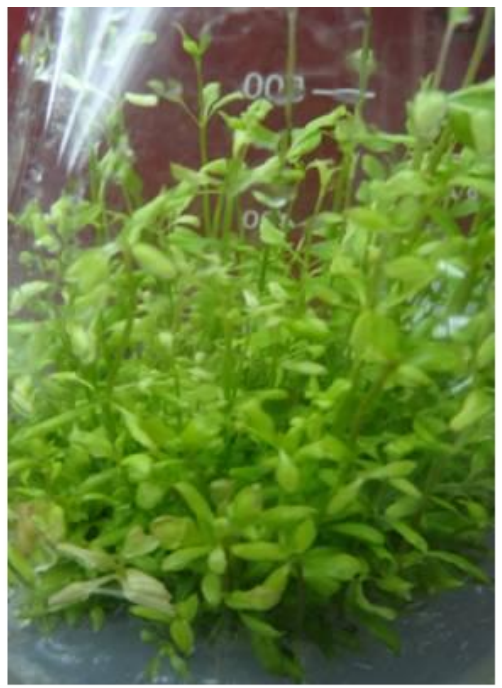

$\mathbf{a}$

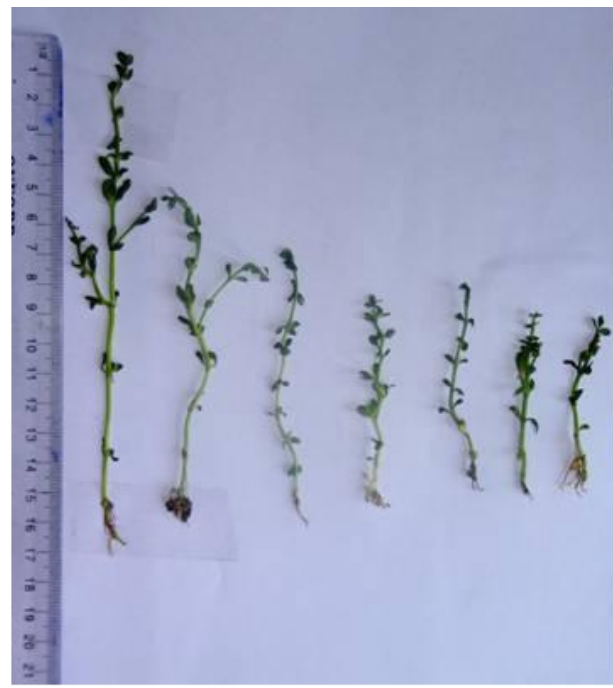

b

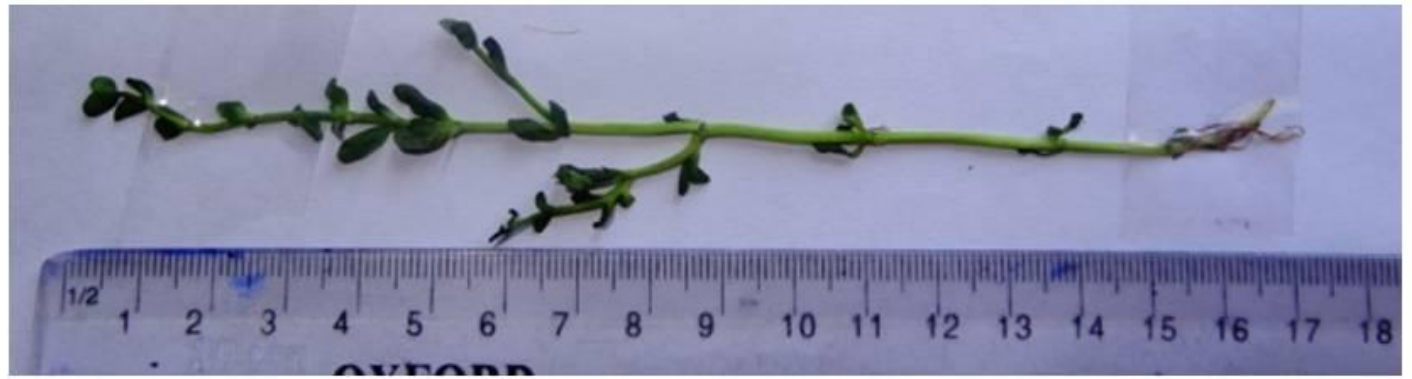

$\mathbf{C}$

Role of plant growth regulators is significant for proliferation and elongation of plants. Cytokinins are the key components to promote direct shooting and flowering. Various workers reported the role of cytokinins for shoot bud induction (Rahman et al., 2013; Sanousi et al., 2014; Mantovani et al., 2013; Dohling et al., 2012; Premkumar et al., 2011). In this investigation, two cytokinins i.e., BAP and KN were used alone or in different combinations for shoot induction from explants. An increase in number of shoots i.e. 128 shoots per explant and about four fold increase in shoot length were observed with optimal MS medium augmented with $1.5 \mathrm{mg} / \mathrm{GA}_{3}$, which are significantly higher in number and length of shoots than the previous reports. This may be due to the reason that $\mathrm{GA}_{3}$ promotes cell division and internodal elongation (Taiz and Zeiger, 2010). Our results are in accordance with findings of other researchers (Behera et al., 2015; Kumar et al., 2012 and Srivastava and Raghav, 2014), wherein they have also reported the addition of $\mathrm{GA}_{3}$ to basal medium monitoring shoot proliferation and elongation.

Moreover, Mittal et al., (2017) reported that the length of the shoots was higher when plant growth regulators were used in combination as compared to when single plant growth regulator was used. 
IBA is the most commonly used PGR for in vitro root induction. Half strength MS medium containing auxin (IBA) produced more roots than media containing full strength MS salts. Half strength MS media leads to starvation of cultures, which leads to forced induction of roots in plants. When such media is supplemented with root inducing hormone such as auxin, it further promotes rooting in plants. In the present study, the best results were obtained with $1 / 2 \mathrm{MS}$ medium augmented with $1.0 \mathrm{mg} / \mathrm{l} \mathrm{IBA}$. Many plant species have been reported to root best in the half strength MS medium (Ceasar et al., 2010; Faisal and Anis, 2005; Franklin et al., 2004 and Liu et $a l ., 2006)$. The IBA treatment was reported to be the best for the root induction of $B$. monnieri (Ceasar et al., 2010). Now-a-days ex vitro rooting, i.e., simultaneous rooting and acclimatization is becoming popular due to significant reduction of time and cost of micropropagation.

Also, in this study we could achieve plant acclimatization in green house irrespective of the potting mixture. The best results were observed with Sand + Soil + FYM (1:1:1) planting media yielding root length of $10.5 \pm 0.41 \mathrm{~cm}$ after three weeks of transfer. Thus, the results obtained here suggest efficiency and reproducibility of the protocol for plantlet regeneration from this ethnomedicinally important plant. It provides a prospective technology for micropropagating at upscale level and conservation of this important medicinal herb for the requirement of future generations.

In this study, an efficient, reproducible plant regeneration protocol for $B$. monnieri using nodal segments of axillary buds has been successfully developed (Fig. 1a to 1f). The regenerated plants will act as reservoir resource for commercial secondary metabolite extraction of important compounds. By this, demand from naturally growing population will be reduced. Hence, this protocol will indirectly remain useful for conservation of this species of Brahmi.

\section{Acknowledgements}

The authors are grateful to Director Research, SKAUST-Jammu, for providing necessary facilities for successful completion of the research work.

\section{Author contributions}

MMS and RKS conceived and planned the work; LMG provided the plant material from Herbal Garden; MG and MMS designed the experiments and wrote the manuscript; MG and MS performed the experiments and analyzed the data; AKS supervised the experiments; all authors approved the final manuscript.

\section{Compliance with ethical standards}

\section{Conflict of interest}

The authors declare that they have no conflict of interest.

\section{References}

Anonymous (2007). National Medicinal Plants Board (NMPB) and Technology Information Forecasting and Assessment Council (TIFAC), Department of Science and Technology, Government of India http://www.nmpb. nic.in/prioritisedmedicinalplants.htm

Behera S, Nayak N, Shasmita, Barik DP, Naik SK (2015) An efficient micropropagation protocol of Bacopa monnieri (L.) Pennell through two-stage culture of nodal segments and ex vitro acclimatization. J Appl Biol \& Biotechnol 3:016-021 
Ceasar SA, Maxwell SL, Prasad KB, Karthigan M, Ignacimuthu S (2010) Highly efficient shoot regeneration of Bacopa monnieri (L.) using a two-stage culture procedure and assessment of genetic integrity of micro propagated plants by RAPD. Acta Physiologiae Plantarum 32: 443452

Franklin F, Sheeba CJ, Lakshmi Sita G (2004) Regeneration of eggplant (Solanum melongena L.) from root explants. In vitro Cell Dev Biol-Plant 40:188-191

Hussain K, Abdussalam AK, Ratheesh CP, Nabeesa S (2011) Heavy metal accumulation potential and medicinal property of Bacopa monnieri- a paradox. Journal Of Stress Physiology and Biochemistry 7:4

Kaur J, Nautiyal K, Pant M (2013) In vitro propagation of Bacopa monnieri (L.) Wettst - A medicinally priced herb. International Journal of Current Microbiology and Applied Sciences 2:131- 138

Kharde AV, Chavan NS, Chandre MA, Autade RH, Khetmalas MB (2017) In Vitro enhancement of bacoside in Brahmi (Bacopa monnieri) using colchicine. J Plant Biochem Physiol 5:1

Kumar V, Kumar V, Umrao V, Singh M (2012) Effect of $\mathrm{GA}_{3}$ and IAA on growth and flowering of carnation. Hort Flora Res Spect 1:69-72

Liu HJ, Xu Y, Liu YJ, Liu CZ (2006) Plant regeneration from leaf explants of Rhodiola fastigiata. In Vitro Cell Dev Biol-Plant 42:345-347

Faisal M, Anis M (2005) An efficient in vitro method for mass propagation of Tylophora indica. Biologia Plantarum 49:257-260

Mantovani A, Biswas SK, Galdiero MR, Sica A, Locati M (2013) Macrophage plasticity and polarization in tissue repair and remodeling. J Pathol 229:176-185

Mehta J, Ansari R, Syedy M, Khan S, Sharma S, Gupta N, Rathore R, Vaishnav K (2012) An effective method for high frequency multiple shoots regeneration and callus induction of Bacopa monnieri (L.) Pennel: An important medicinal plant. Asian J Plant Sci Res 2:629-626

Mishra SK, Tiwari KN, Shivna PL, Mishra AK (2015) Micropropagation and Comparative Phytochemical, Antioxidant Study of Bacopa monnieri (L.) Pennell. Research Journal of Pharmaceutical, Biological and Chemical Sciences 6:902-912

Mittal J, Mishra Y, Singh A, Batra A, Sharma MM (2017) An efficient micropropagation of Tinospora cordifolia (Willd.) Miers ex Hook F \& Thoms: A NMPB prioritized medicinal plant. Indian Journal of Biotechnology 16: $133-137$

Mohanta YK, Sahoo S (2014) In vitro culture of highly valuable medicinal plant Bacopa monnieri (L.) Penn. for rapid and mass multiplication. International Journal of Pharmaceutical Science Invention 3:41-45

Murashige, T Skoog F(1962) A revised medium for rapid growth and bioassays with tobacco tissue cultures. Physiol Plant 15:473-97

Premkumar G, Sankaranarayanan R, Jeeva S, Rajarathinam K (2011) Cytokinin induced shoot regeneration and flowering of Scoparia dulcis L. (Scrophulariaceae)-an ethnomedicinal herb. Asian Pacific Journal of Tropical Biomedicine 1:169-172

Purohit S, Jugran AK, Bhatt ID, Palni LMS, Bhatt A, Nandi SK (2017) In vitro approaches for conservation and reducing juvenility of Zanthoxylum armatum DC: an endangered medicinal 
plant of Himalayan region. Trees 31:1101-1108

Rahman S, Biswas N, Hassan MM, Ahmed MG, Mamun A, Islam MR, Moniruzzaman M, Haque ME (2013) Micro Propagation of Banana (Musa sp.) cv. Agnishwar by in vitro Shoot Tip Culture. International Research Journal of Biotechnology 4:83-88

Rathore S, Singh N (2013) In vitro conservation of Bacopa monnieri - an endangered medicinal plant. Global J Biosci Biotechnol 2:187-19

Dohling S, Kumaria S, Tandon P (2012) Multiple shoot induction from axillary bud cultures of the medicinal orchid, Dendrobium longicornu. AoB Plants 10.1093/aobpla/pls032

Sanousi RSE, Hassan SM, Mohammed IA (2014) In vitro shoot initiation and multiplication of Jojoba

Simmondsiachinensis (Link.) Schneider. Advances in Life Sciences 4:131-134

Shahzad A, Parveen S, Sharma S, Shaheen A, Saeed T, Yadav V, Akhtar R, Ahmad Z, Upadhyay A (2017) Plant Tissue Culture: Applications in Plant Improvement and Conservation. In Plant Biotechnology: Principles and Applications (pp. 37-72) Springer Singapore
Shrivastava N, Rajani M (1999) Multiple shoot regeneration and tissue culture studies on Bacopa monnieri (L.) Pennell. Plant Cell Rep 18:919-923

Smith R (2005).Water System design. In: Chemical Process Design and Integration. John Wiley \& Sons Ltd, The Atrium, Southern Gate, Chichester, U.K. pp 581-648

Srivastava J, Raghav PK (2014) Effect of different Gibberellic acid concentration on Pigeon pea (Cajanus cajan [L.] millsp.) cv. manak (h77216) via cotyledonary node explants. International Journal of Advanced Biotechnology and Research 5:151-156

Taiz L, Zeiger E (2010) Plant Physiology. 5th Edition, Sinauer Associates, Inc., Sunderland

Tripathi N, Chouhan DS, Saini N, Tiwari S (2012) Assessment of genetic variations among highly endangered medicinal plant Bacopa monnieri (L.) from Central India using RAPD and ISSR analysis. 3 Biotech 2:327-336.

Witbooi H, Kambizi L, Makunga NP (2017) Micropropagation and the production of secondary metabolites in Agathosma betulina (Berg.): An important aromatic ethnomedicinal plant, South African Journal of Botany 109:375-376.

\section{How to cite this article:}

Manmohan Sharma, Mehak Gupta, R.K. Salgotra, Mamta Sharma, A.K. Singh and Gupta, L.M. 2018. Scaling up of Protocol for in vitro Multiplication and Conservation of Elite Genotype of Bacopa monnieri L. Pennell. Int.J.Curr.Microbiol.App.Sci. 7(10): 3225-3236. doi: https://doi.org/10.20546/ijcmas.2018.710.374 